\title{
Francis Kasten
}

\section{Die »Terminshoheit« des Gerichts und das Recht auf Verteidigung}

Zur Terminierung und Vertagung der Hauptverhandlung bei Verhinderung des Verteidigers

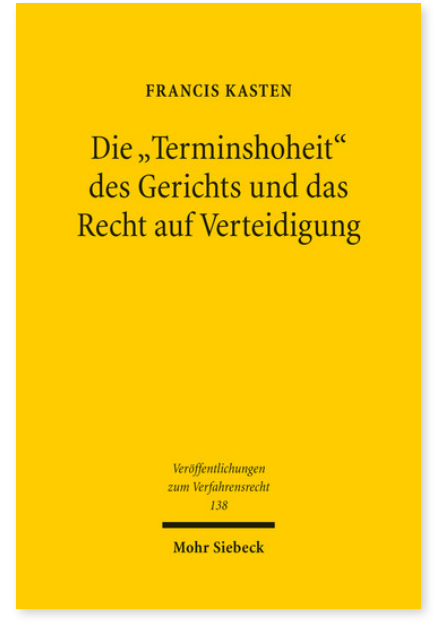

2017. XX, 358 Seiten. VVerfR 138

ISBN 978-3-16-155311-0

DOI 10.1628/978-3-16-155311-0

eBook PDF 99,00€

ISBN 978-3-16-155310-3

fadengeheftete Broschur 99,00€
§ 137 StPO garantiert dem Angeklagten ein uneingeschränktes Recht auf Beistand eines Verteidigers und somit auch die Anwesenheit des Verteidigers in der Hauptverhandlung. Dieses Recht des Angeklagten wird faktisch durch die Terminierung der Hauptverhandlung eingeschränkt. Die Rechtsprechung geht von einer in § 213 StPO normierten Terminshoheit des Vorsitzenden aus und versteht § 228 Abs. 2 StPO als Einschränkung des § 137 StPO für die Terminierung und Vertagung der Hauptverhandlung. Francis Kasten gibt eine Übersicht über die umfangreiche Rechtsprechung und untersucht, ob die Terminierungspraxis mit den Grundrechten des Angeklagten in Einklang zu bringen ist. Dazu werden Aspekte wie die Zumutbarkeit der Selbstverteidigung, das Beschleunigungsgebot und Belange der Strafrechtspflege genauer betrachtet. Die Arbeit bietet zudem eine bisher in der Strafrechtswissenschaft fehlende systematische Auslegung von § 213 StPO und § 228 Abs. 2 StPO.

Francis Kasten Geboren 1978; Magister-Studium Geschichte und Sozialwissenschaften an den Universitäten Bielefeld und Wuppertal; Studium der Rechtswissenschaften an der Ruhr-Universität Bochum; 2006 Erste juristische Staatsprüfung; 2009 Zweite juristische Staatsprüfung; 2016 Promotion; 2016 Richter im Bezirk des LSG NRW und Zuweisung an das Sozialgericht Duisburg.
Jetzt bestellen:

https://mohrsiebeck.com/buch/die-terminshoheit-des-gerichts-und-das-recht-auf-verteidigung-9783161553110?no_cache=1 order@mohrsiebeck.com

Telefon: +49 (0)7071-923-17

Telefax: +49(0)7071-51104 